\title{
Editorial
}

\section{Standing Up For Peer Review}

$\mathrm{T}$ he papers in Antarctic Science are all peer reviewed, as in most scholarly publications. This process of constructive and objective critical evaluation of scientific work is at the core of the scientific method and provides confidence to the reader in the data and conclusions reported in a paper. When done well, it improves papers greatly in terms of both rigour and clarity. This process depends entirely on the collective self-interest and good will of the scientific community. We need to have our papers reviewed for publication and a key job for editors of scientific journals is to identify and invite suitable reviewers. Many thousands of scientists undertake this work every year but our editors and others are reporting increasing difficulty finding scientists willing to review submitted papers. Demands on the time of all members of the scientific community are many and increasing, but if we fail to accept this obligation then the whole scientific process is endangered.

So, the first message of this editorial is a plea to all its readers to engage in this process whenever possible. Our unpaid editors fully understand the pressures on your time, but need your help to keep the peer review process going, recognising that there will be times when you cannot accept an invitation to do a review for really good reasons. The second message is to ask scientists to respond promptly to invitations, and if you cannot accept please tell us and suggest alternates. When you accept an invitation, please complete the review in a timely manner. Put simply, you cannot complain about the slow review of your own manuscript while being slow or unwilling to review the papers of others.

In addition to these simple pleas for your help and support with peer review, Antarctic Science has decided to make some changes to our practices to improve and celebrate the community's contribution to the peer review process.

1. We will establish a system by which reviewers are told the outcome of editorial decisions on papers they have reviewed.

2. We will publish annually, on our website, the names of all the reviewers for that year. We hope that this acknowledgement will be valuable, particularly for early career researchers in their career development, and will publically acknowledge the reviewer's contribution, while maintaining the anonymity of the peer review process for reviewers who choose to review anonymously. The editors will also highlight, alongside this list, a few scientists for their exceptionally valuable reviews in that year.

3. We believe that early-career scientists make excellent reviewers and that participating in this process will help their own development as scientists. However, it is often difficult for editors to identify such scientists because, inevitably, they have fewer publications and citations. We are therefore going to make a particular effort to more closely engage this community in the peer review process. We will encourage senior researchers unable to do a particular review, to suggest the names of younger scientists who they feel would be suitable reviewers for that paper. We will also engage with younger scientist networks via organisations such as APECS and SCAR, providing mentoring as appropriate.

4. We will encourage reviewers and authors to provide feedback to Editors on their experience with the peer review process at Antarctic Science

We hope this way we can improve the speed and quality of the peer review process to ensure that Antarctic Science remains as a primary source of important and high quality papers across the disciplines. We look forward to your support in this process.

The Editors and Board of Antarctic Science Ltd 